\title{
Second Trimester
}

National Cancer Institute

\section{Source}

National Cancer Institute. Second Trimester. NCI Thesaurus. Code C92876.

The period of gestation that ranges from the 13th to the 27th week of pregnancy. 